\title{
Parcerias entre Setor Público e Privado no Desenvolvimento Turístico de Piracicaba - SP
}

\author{
Partnerships between Public and Private Sectors in the \\ Tourism Development of Piracicaba - SP
}

Renata Sarto Rocha ${ }^{1}$

RESUMO: Parcerias são as junções de forças e interesses em comum dos diversos setores relacionados com o turismo de uma localidade e que devem fazer parte da política pública de turismo. Este trabalho mostra a importância das parcerias para o desenvolvimento turístico local, a origem das políticas públicas de turismo, seu elo com as parcerias e, principalmente, as dificuldades encontradas na viabilização daquelas entre os setores público e privado, analisando o modo de ver de ambos os lados interessados do município de Piracicaba (sp). Nesta pesquisa, o levantamento das informações foi feito por meio de entrevistas realizadas nos setores público e privado. E, como forma de resolução do problema, foi proposta a criação de parcerias entre os diversos segmentos ligados ao turismo municipal.

PALAVRAS-CHAVE: parcerias; políticas públicas de turismo; iniciativa privada; setor público; Piracicaba - São Paulo, Brasil.

ABSTRACT: Partnerships are the junctions of forces and interests in common of the several sections related to the tourism of a place in which should be part of the public tourism policies. This work shows the importance of the partnerships for the tourist development of the place, it also shows the origin of the public tourism policies, its link with the partnerships and mainly the difficulties found in their feasibility between the public and private sectors, analyzing the way of seeing both interested sides of the district of Piracicaba (sP). In this research the rising of the informations was through interviews

1. Bacharel em Turismo pela puc de Campinas. Contato: Rua Ajudante Albano, 665 - 13416-030

- Piracicaba-sp; e-mail: renatasarto@ig.com.br. 
accomplished in the public and private sectors. And as form of resolution of the problem, the creation of partnerships was proposed among the several segments linked to the municipal tourism.

KEYWORDS: partnerships; public tourism policies; private initiative; public sector; Piracicaba - São Paulo (State), Brazil.

\section{Introdução}

Piracicaba está situada a 160 quilômetros da capital paulista, em uma das regiões mais industrializadas e produtivas do Estado de São Paulo e do País. A cidade integra o Comitê das Bacias Hidrográficas dos rios Piracicaba, Capivari e Jundiaí, que reúne 57 municípios (Mourão, 2001). No ano 2000, a sua população atingiu 328.312 habitantes, o que significou crescimento anual médio de 1,68\% na década (Mourão, 2001).

Em Piracicaba, a qualidade de vida é um dos maiores atrativos. Cortada pelo rio de mesmo nome, a cidade passa por uma ampla revitalização urbana e ambiental, o que tem conferido um aspecto visual ainda mais agradável. Piracicaba é uma das únicas cidades no Brasil a ter implantado seu Planejamento Estratégico, com base nos princípios da Agenda 21, por meio do Projeto Piracicaba 2010 (transformado em ONG), com vistas ao seu desenvolvimento sustentável. Exemplo de prática de responsabilidade social, o "Piracicaba 2010" envolveu todos os segmentos da sociedade civil organizada, inclusive o governo municipal (Prefeitura, 2004).

Para a realização de vários projetos como este, principalmente na área de turismo, o setor público necessita de parcerias (união de pessoas ou empresas, a fim de interesse comum [Aurélio, 1986]), para facilitar a sua viabilização, pois, neste setor, mesmo "a cidade" sabendo de sua importância, os recursos disponíveis ainda são muito baixos, impedindo que o poder público consiga sozinho realizar projetos. Contudo, essas parcerias são de profunda importância para o turismo de Piracicaba ou de qualquer outra cidade.

Como, no poder público, tudo é trabalhado por meio de políticas, no turismo não seria diferente. Portanto, "a política de turismo pode ser definida como um conjunto de regulamentações, regras, diretrizes, diretivas, objetivos e estratégias de desenvolvimento e promoção que fornece uma estrutura na qual são tomadas as decisões coletivas e individuais que afetam diretamente o desenvolvimento turístico e as atividades diárias dentro de uma destinação" (Goeldner et al., 2003). A importância desta política é garantir que o local tenha uma idéia clara de que direção está tomando ou o que busca tornar-se em longo prazo. Ela deve lutar para criar um ambiente no qual a colaboração entre os maiores interessados no turismo seja apoiada e facilitada. A política de turismo preenche, entre outras, a função de fornecer uma estrutura para discussões públicas e privadas sobre o papel e as contribuições do setor turístico para a economia e para a sociedade em geral.

De acordo com o Plano Nacional de Turismo (2003-2007), as várias interfaces para o desenvolvimento do turismo necessitam de uma permanente articulação entre os diversos setores públicos e privados, no sentido de agilizar soluções, eliminar entraves burocráticos, compartilhar decisões e facilitar a participação de todos os envolvidos no processo de crescimento do setor.

Segundo Nogueira (1983), a política nacional de turismo é (ou, pelo menos, deveria ser) o elo integrador entre a esfera governamental representada pelos segmentos oficiais do sistema e os beneficiários e usuários dessa política.

Há um corpo crescente de opinião que sugere que o envolvimento do setor privado não deve ser limitado ao fornecimento de serviços turísticos, mas também estar envolvido com o planejamento e a formulação de políticas de Turismo. A importância de arranjos envolvendo a comunidade anfitriã em parceria com os governos locais em políticas de Turismo também tem sido muito divulgada (Jenkins, 1994; Long, 1994 apud Pereira, 1999).

Essas parcerias têm aumentado muito nos últimos anos, porém devem ser ainda mais estimuladas, pois, com a junção de forças e interesses de todas as partes, fica muito mais fácil desenvolver projetos e estabelecer metas para o melhoramento turístico da localidade.

\section{Politica de turismo no Brasil}

A origem das políticas públicas de turismo dá-se no período posterior à Segunda Guerra Mundial, marcada pela regulamentação do trabalho, da limitação do seu tempo, férias remuneradas, da aposentadoria, além de outras conquistas da sociedade moderna. O nascimento das políticas públicas está relacionado à tentativa de gerar conhecimento aplicável às ações práticas dos governos, com ênfase na preocupação com a qualidade e eficácia da intervenção pública. A consolidação dessas políticas deve ser a manifestação primeira de uma conscientização governamental para a importância do turismo como instrumento de crescimento econômico, geração de renda e melhoria da qualidade de vida da população (Pereira, 1999).

Em julho de 1992, foi elaborado o Plano Nacional de Turismo (Plantur), com seus objetivos voltados para reestruturação do turismo, a partir da parceria entre o setor público e privado. Porém, desde a criação da EmBratur, em 1966, nada de 
muito significativo ocorreu em termos de estruturação, sistematização e implementação da política nacional de turismo, que somente aconteceu em março de 1996, com a reformulação dos antigos ordenamentos (Cavalcante \& Hora, 2002).

O documento que criou a Política Nacional de Turismo, preconizada pelo Decreto no 448/92 e instituída em 1996 - primeiro mandato do Governo FHC (1995-1998), é o mais completo e detalhado documento oficial na história das políticas federais no setor de turismo. Contudo, não implica, necessariamente, maior eficiência com relação às políticas anteriores. A política de turismo, por ser setorial, somente pode ser bem-sucedida se articulada com outras políticas setoriais e se entendida como uma pequena parte de um imenso jogo de relações (Cruz, 2000). Nota-se que possuir o melhor documento da história do turismo não significa nada, se não existir vontade de mudança e, principalmente, se não houver articulações entre os vários setores, tanto públicos como privados, responsáveis por todo o processo turístico de uma localidade ou de um país.

A política nacional de turismo é o elo integrador entre a esfera governamental representada pelos segmentos oficiais do sistema, e os beneficiários e usuários dessa política. No seu interior, encontram-se diretrizes ou políticas básicas que expressam os caminhos para atingir os objetivos nacionais para o turismo. O desdobramento dessas políticas básicas em programas de execução, acompanhados da indicação dos projetos, envolve os instrumentos do planejamento necessário à implementação do setor (Nogueira, 1983).

Na estrutura da administração pública do turismo há variações consideráveis que, por sua vez, dependem do tamanho da atividade turística e da importância que o governo dá às várias razões apresentadas para o envolvimento do setor público no turismo (Cooper et al., 2001). Há uma tendência acentuada para que, na mudança do governo de um país, sejam modificadas também a orientação do turismo e sua posição hierárquica na administração pública. Isso provoca alterações na chamada organização institucional do setor (Beni, 1991). De acordo com Ignarra (2003), quanto maior o desenvolvimento do turismo em um país, maior será a estruturação pública do setor. Nota-se que, aos poucos, estão descobrindo no Brasil a importância do turismo para a economia e, com isso, sua posição na administração pública vem aumentando, sendo até em alguns Estados prioridade governamental, mas ainda há muito que deve ser mudado para que ele se torne parte das prioridades nacionais.

No turismo, o papel das políticas públicas deveria ser o de propiciar o desenvolvimento harmônico dessa atividade. Cabe ao Estado construir a infra-estrutura de acesso e a infra-estrutura básica urbana - que também atenda à população local - e prover de uma superestrutura jurídico-administrativa (secretarias e similares), cujo papel é planejar e controlar os investimentos que o Estado realiza - que permitem o desenvolvimento da iniciativa privada, encarregada de construir os equipamentos e prestar os serviços - para que retornem na forma de benefícios a toda a sociedade (Barreto, Burgos \& Frenkel, 2003). A intervenção do Estado no desenvolvimento do turismo é muito importante, principalmente nos países em desenvolvimento, em conseqüência do pouco capital e da ausência de talentos. Com isso, a ação do governo torna-se necessária a fim de abrir novas áreas para o turismo, onde os riscos são muitos altos para o setor privado (Bennett, 1994 apud Pereira, 1999).

É importante observar também que existem exemplos freqüentes nos quais é a incerteza, como em tempos de recessão, mais do que o potencial limitado, que impede o setor privado de investir. Nessas situações, Cooper et al. (2001) afirmam que o principal papel da intervenção governamental é atuar como um catalisador para dar confiança aos investidores. Sendo assim, os fundos públicos serão capazes de alavancar dinheiro privado, por meio do compromisso do governo com o turismo, possibilitando, portanto, que o potencial de mercado turístico de uma área ou, até mesmo, de toda uma região seja alcançado. Porém, o poder público deve ter cuidado, pois pode desestimular a iniciativa privada, criando, sem captar a fundo a essência da atividade turística, instrumentos legais que, em face de sua multiplicidade, podem gerar dificuldades operacionais para as empresas que atuam no turismo (Pereira, 1999 apud Alexandre, 2003).

\section{A importância das parcerias}

O turismo é um produto multifacetado que inclui hospedagem, alimentação, transportes, agenciamento, facilidades de compras, atrativos, infra-estrutura básica e modo de vida da comunidade receptiva. Assim, o desenvolvimento turístico exitoso é sempre fruto da parceria entre os vários partícipes da atividade turística, que são capazes de satisfazer as exigências dos consumidores. Partindo-se do pressuposto de que a parceria entre elementos tão díspares é difícil e complexa, é necessário que as medidas referentes ao planejamento sejam tomadas pelo governo. O turismo é uma atividade econômica que tem no território, na paisagem e nos patrimônios natural e cultural sua principal matéria-prima. Assim, não é possível se produzir sem que haja, direta ou indiretamente, uma participação do poder público. Deste modo, o desenvolvimento do setor turístico tem na ação governamental um elemento estratégico para o seu crescimento. Na maior parte dos países, o turismo é uma atividade desenvolvida a partir da ação conjunta entre a iniciativa privada e o setor público. A forma desta parceria depende da orientação socioeconômica e da política de cada país (Ignarra, 2003). 
A parceria entre os setores é muito importante para o bom andamento de projetos de turismo de qualquer localidade. Pereira (1999b) afirma que, além da participação do Estado, é fundamental que haja o envolvimento dos usuários e beneficiários do setor na produção e avaliação de políticas públicas de turismo. Não há planejamento que possa ser implantado de maneira eficiente sem que exista a harmonia dos três setores: poder público, iniciativa privada e comunidade (Migliano, Scatena \& Cunha, 2003).

De acordo com a OMT (2003), é essencial envolver as comunidades no processo de desenvolvimento turístico; é por meio desse envolvimento que elas entenderão o turismo e terão maiores condições de lidar com esse novo desenvolvimento em sua área e de participar dos seus benefícios, sendo assim mais provável que apóiem o turismo. Além disso, as comunidades locais são as que melhor conhecem sua área e sociedade, podendo apresentar boas idéias quanto ao desenvolvimento turístico e às formas de participar desse desenvolvimento. Também segundo Nogueira (1987), torna-se imperativa a participação ativa, consciente, deliberada e decisiva da comunidade no processo de formulação e implementação da política pública de turismo. Institucionalmente, a comunidade deverá estar representada pelos líderes das diversas categorias que a compõem, como empresários, trabalhadores, autoridades locais, regionais, estaduais, meios de comunicação e organizações não-governamentais, entre outros.

No estágio inicial de um projeto de desenvolvimento, a participação dos setores possui inúmeras vantagens, a começar pelo saber compartilhado da problemática local e pela identificação de necessidades essenciais a serem incorporadas à visão do projeto, como dito anteriormente, em que somente a iniciativa privada e a comunidade podem percebê-las, por estarem vivendo aquilo em seu cotidiano.

É importante também reforçar que a atividade turística pode alcançar sucesso quando o poder público e a iniciativa privada encontram-se compactuando com os mesmos interesses (Romero, 2003). Sendo assim, é inconcebível que o setor privado não participe do processo turístico de uma cidade, pois existe quantidade considerável de decisões públicas tomadas pelo setor hoteleiro, de transporte e de outras áreas que operacionalizam o setor turístico, em vista de decisões não tomadas pelo governo e dos vazios da legislação (Nogueira, 1983).

Alguns destes setores que operacionalizam a atividade turística são os órgãos nacionais de turismo, normalmente chamados de Convention \& Visitor Bureaus (CVBS), que são simplesmente associações privadas, cuja constituição é determinada por seus membros, e podem incluir representações do governo. Assim, a renda é oriunda de uma série de fontes e, como outros negócios, a existência desses organismos depende da demanda por seus serviços no mercado. Em tempos de recessão, essas associações costumam ter dificuldades de levantar fundos do setor privado para manter suas atividades e necessitam de injeções de verbas públicas para dar continuidade a projetos de longo prazo (Cooper et al., 2001).

Dentro do produto turístico, existem bens e serviços que não funcionam exclusivamente amparados pelos mecanismos da lei de oferta e procura do mercado. Há itens no turismo que são de uso comum, devendo estar disponíveis para todos. São os bens públicos, cuja característica principal é não serem exclusivos. Há também os bens cujo consumo interessa ao Estado incentivar e que, se dependessem apenas da iniciativa privada, não teriam seu desenvolvimento fomentado (Ignarra, 2003). Portanto, percebe-se que não é possível criar modelos de desenvolvimento sustentado sem uma interferência governamental no processo. O necessário é que haja a interação do governo com o setor privado.

Entretanto, apesar de o turismo no Brasil se constituir, atualmente, numa força econômica de peso e dinamismo, além de possuir visibilidade de política pública, as várias interfaces para o seu desenvolvimento, que necessitam de permanente articulação entre diversos setores públicos e privados, não têm sido fáceis. A desarticulação, além de ser interna, é intersetorial (Cavalcante \& Hora, 2002).

A resistência ao processo participativo na dinâmica de planejamento de projetos é também uma das dificuldades encontradas nas parcerias, e parece ter sua explicação na cultura institucional brasileira e na percepção política de "participação" como divisão de poder das esferas instituídas. Apenas por meio do processo participativo será possível tanto o funcionamento da dinâmica socioeconômica do país como o exercício pleno da cidadania, e a legitimação de estratégias de desenvolvimento conjuntamente construídas (Irving, 2002).

Em muitas destinações turísticas, nota-se que a atividade se desenvolve com um mínimo de ação governamental e essa postura leva a uma ocupação do setor absolutamente desordenada pela iniciativa privada. Em outras, verifica-se o governo explorando serviços típicos da iniciativa privada e fazendo uma concorrência em certo ponto, desleal com as empresas privadas (Ignarra, 2003). Para que isso não ocorra, uma posição do governo em relação aos investimentos turísticos de uma região é fundamental, e também para a definição de qual modelo de desenvolvimento se deseja e qual papel cabe ao empresário privado.

Os reflexos econômicos do engajamento entre os setores público e privado serão visualizados direta e indiretamente a partir do aumento do fluxo turístico e poderão ser revertidos em melhorias da infra-estrutura, incrementos das indústrias associadas ao setor (alimentar, de transportes, etc.) e aumento da demanda de produtos locais, entre outros (Barreto, 1995 apud Vernaglia \& Goulart, 2003), em conseqüência de um planejamento e gestão turística integrados entre os setores (Vernaglia \& Goulart, 2003) 


\section{Papéis dos setores público e privado}

A implementação das políticas e dos planos turísticos exige abordagens e técnicas. As recomendações de planejamento feitas devem ser passíveis de implementação, e os caminhos para implementá-las precisam ser considerados ao longo do processo de planejamento. Tal execução é responsabilidade tanto do governo quanto do setor privado, e os respectivos papéis dos setores público e privado precisam ser claramente definidos no processo de implementação.

Os papéis do setor público no desenvolvimento turístico são a política, o planejamento e a pesquisa, proporcionando uma infra-estrutura básica, desenvolvendo alguns atrativos turísticos, fixando e administrando padrões para instalações e serviços turísticos, estabelecendo e administrando regulamentos para o uso da terra e a proteção ambiental, determinando padrões para a educação e o treinamento para o turismo, além de estimulá-los, mantendo a segurança e a saúde pública e algumas funções de marketing. Oferecer incentivos para atrair investimentos do setor privado ou, mesmo, arriscar-se em conjunto com o setor privado em alguns projetos também pode ser necessário para encorajar a iniciativa privada no desenvolvimento. O compromisso político pelo desenvolvimento do turismo de modo planejado e sustentado é essencial para proporcionar a base para a sua implementação. A conquista desse compromisso normalmente exige a educação de elaboradores de políticas quanto à importância potencial do turismo na área e à necessidade de desenvolvê-lo obedecendo aos padrões sustentáveis.

Já o setor privado é geralmente responsável pelo desenvolvimento de hospedagens, operações de viagem e passeios, por outros empreendimentos turísticos comerciais e de infra-estrutura do local a eles relacionada, por alguns atrativos turísticos e por atividades de marketing. O setor privado também deve assumir algumas funções reguladoras de manutenção dos padrões de qualidade da indústria turística, por intermédio de associações turísticas do setor privado. Grande parte da infra-estrutura pode ser fornecida pelas empresas privadas de serviços públicos ou por sociedades públicas, com o emprego das taxas de utilização no pagamento dos custos operacionais e de investimento incluídos.

É essencial manter uma cooperação e uma coordenação perfeita entre os setores público e privado, ao longo do processo de planejamento e implementação, de modo que o desenvolvimento seja coordenado e direcionado para o alcance de objetivos comuns. Um mecanismo organizacional usual consiste em estabelecer um órgão que coordene o turismo na área, tal como uma junta de consultoria turística ou comitê coordenador, compreendendo representantes do governo e do setor privado. Esse órgão se reúne regularmente para refletir sobre questões turísticas de interesse mútuo, trocar idéias e informações, aconselhar as autoridades responsáveis a agirem de forma apropriada e coordenar o patrocínio conjunto de alguns projetos. Além disso, é necessário que haja contatos informais contínuos entre as autoridades governamentais e os empreendimentos privados (informações obtidas no livro da омт, 2003).

Quando realmente se pretende alcançar objetivos desejados ao final do planejamento, faz-se necessária a existência de um monitoramento de tempos em tempos, para saber se é preciso haver correção no andamento do projeto e em que estágio ele se encontra. Isso deve ocorrer, qualquer que seja seu tipo.

\section{Turismo em Piracicaba}

Atualmente, o turismo em Piracicaba é quase exclusivamente de negócios. No período de segunda a quinta-feira, quase $90 \%$ da ocupação da rede hoteleira da cidade deve-se a esse tipo de turismo. O turismo de negócios vem crescendo em Piracicaba devido à existência de importantes instituições de ensino superior, centros de pesquisa e indústrias no Município, cujos eventos atraem a visita de estudiosos, pesquisadores e executivos.

Piracicaba dispõe de uma boa rede gastronômica, com restaurantes e bares concentrados em certas áreas ou localizados em pontos turísticos. Porém, em algumas regiões, precisariam ser melhorados a fiscalização sanitária e os aspectos receptivos, como a disponibilidade de estacionamento para ônibus de turismo.

A cidade oferece belezas naturais e construídas de grande interesse, como a piracema vista da orla, os grandes parques, a ESALQ, a rua do Porto, o bairro Monte Alegre e toda a orla do rio. Merece destaque também o Parque do Engenho Central: por sua beleza natural e pelo significado histórico de suas edificações, às margens do rio Piracicaba, tem grande potencial para atividades turísticas e culturais.

Piracicaba ainda se diferencia por sua história marcante e pelas tradições que preserva. São diversas as festas, os grupos folclóricos atuantes, as companhias de teatro e os artistas locais, em especial nas artes plásticas e na música, os quais promovem eventos de nível nacional e internacional.

Entretanto, o turismo de lazer praticamente inexiste em Piracicaba. Esse tipo de turismo depende, para seu desenvolvimento, de um atrativo maior, mobilizador, como, por exemplo, o Rio Piracicaba. Na cidade, existe também a oportunidade no turismo rural, devido à existência de serras, cachoeiras, trilhas, fazendas e sítios arqueológicos, que mereceriam um trabalho de desenvolvimento integrado.

Em síntese, o turismo de lazer poderá desenvolver-se em Piracicaba dentro do contexto da sustentabilidade ambiental e com a participação da comunidade (Mourão, 2001). 


\section{Justificativa do tema}

Apesar de haver muitas parcerias, ainda existem cidades que não as realizam ou apresentam dificuldades em seu funcionamento, podendo interferir no desenvolvimento de projetos. Portanto, a importância da realização deste trabalho foi mostrar as dificuldades encontradas pelos setores (público e privado) para a viabilização dessas parcerias no município de Piracicaba.

\section{Objetivos}

Geral: levantar a existência de parcerias entre os setores público e privado no desenvolvimento turístico de Piracicaba, e quais são as empresas pertencentes.

Especifico: verificar o funcionamento e as dificuldades encontradas na viabilização das parcerias no setor de turismo de Piracicaba.

\section{Metodologia}

Neste trabalho, o levantamento bibliográfico e documental foi realizado por meio de consultas às principais obras e revistas científicas da área, as quais foram utilizadas como fundamentação teórica desta pesquisa.

A coleta de dados deu-se através de entrevistas pessoais já estruturadas, realizadas com os respectivos setores, público e privado, sendo utilizado para ambos o mesmo questionário, a fim de que fossem possíveis as comparações das respostas. Para a elaboração do referido questionário, foram consultados os livros Métodos e técnicas de pesquisa em turismo (Dencker, 1998) e Turismo: princípios e práticas (Cooper et al., 2001). Este questionário incluía as seguintes perguntas:

Existem parcerias entre os setores público e privado?

Se existem:

Em quais projetos são? Desde quando?

Como funciona esta parceria?

De quem partiu a iniciativa para a parceria?

Quais as principais dificuldades encontradas?

Por que essas dificuldades ocorrem?

Quais as possíveis alternativas para solucioná-las?

Se não existem parcerias:

Quais os motivos de não haver parcerias entre os setores?
Há possibilidade de haver parcerias entre os setores (público e privado)? Por que elas não ocorrem? Quais as principais dificuldades encontradas? Por que essas dificuldades ocorrem?

Quais as possíveis alternativas para solucioná-las?

Como poderia ser realizada parceria entre esses setores?

Essas entrevistas foram, após o consentimento dos informantes, gravadas.

O levantamento da existência de parceiros foi efetuado através de informações concedidas pela Secretaria de Turismo. Os entrevistados foram oito pessoas, sendo três do setor público e cinco do privado. As entrevistas foram a principal fonte de informação desta pesquisa. E, para o tratamento dos resultados, realizaram-se análises e comparações das informações obtidas pelas entrevistas de forma qualitativa, podendo assim chegar-se a uma conclusão e ao objetivo proposto.

\section{Resultados}

As informações constantes desta pesquisa foram obtidas através dos entrevistados, sendo introduzidas somente falas consideradas relevantes.

Os entrevistados do setor público foram os funcionários da Secretaria de Turismo de Piracicaba (sETuR), Adele Françoso (responsável pelo setor de eventos, projetos e pesquisas), Roberta Lessa (coordenadora de projetos, pesquisa e difusão) e o Secretário de Turismo, Paulo Lopes.

Já no privado, os entrevistados foram os devidos responsáveis pelas empresas: Ronaldo Taveira Marques, gerente comercial do Bristol Center Flat, Álvaro França, dono da agência Planeje Turismo; Volmir Dalan, gerente-geral do restaurante Le Gourmet; Márcia Pinho de Souza Pinto, gerente-geral do Íbis Hotel Piracicaba; e Mauro Roberto Teixeira Junior, gerente administrativo do New Life Apart Hotel.

Nas entrevistas realizadas no setor público, mais precisamente na Secretaria de Turismo de Piracicaba (SETUR), as funcionárias afirmam a inexistência de parcerias entre os setores, pois falta iniciativa do setor público para a realização de algo que conscientize a comunidade e, também, as empresas privadas sobre a importância do turismo e de parcerias entre os setores para o município. É necessário ainda que haja a procura por pequenos e médios parceiros para a realização de nossos projetos, mas isso fica sob responsabilidade do Secretário que, por sua vez, não o faz. Há vários projetos que poderiam estar sendo trabalhados, já em fase de iniciação, e que estão parados por faltas dessas parcerias.

Outra dificuldade, segundo elas, são as empresas, como os hotéis, que parecem não ter o costume de unir-se com os outros segmentos, não dando tanta 
importância a este assunto, pois conseguem sobreviver sozinhas, acreditando estar bem como estão, não tendo a consciência da verdadeira importância do turismo e como este pode melhorar e muito seus estabelecimentos.

Uma possível solução para esse problema, segundo as funcionárias, é conscientizar a população e convidar as partes interessadas no turismo, como hotelaria, agências, a UNIMEP (com sua Faculdade de Turismo) e todas as empresas afins, junto com a Secretaria de Turismo, a terem uma linha de ação conjunta. É preciso que todos falem a mesma língua, e não é isso que parece acontecer.

Sob a visão do Secretário, a procura das empresas não deveria estar centrada na SETUR, sendo que, neste ano, foi criado o Convention \& Visitor Bureaus (CVB), cuja função é organizar todas as partes afins, todas as empresas do trade turístico dentro de um único órgão, gerindo o mesmo. Ele afirma que as empresas privadas não precisam da Secretaria de Turismo, e que é a secretaria que precisa delas para que continuem fomentando as atividades na cidade. E eles, enquanto secretaria, dão mais ênfase a este fomento. Portanto, segundo ele, a solução para a parceria seria o CVB, que faz a união entre as empresas, pois o poder público tem de estar dentro do projeto, mas como parceiro, e não como financiador ou responsável/ fundador daquele.

No setor privado, sob o modo de ver dos responsáveis pelas empresas, as dificuldades encontradas na não-existência de parcerias seria, primeiramente, a falta de apoio à iniciativa do órgão público, pois é ele que deve ter a atitude inicial, através da Secretaria de Turismo, de reunir, chamar a iniciativa privada, aqueles que fazem parte do trade turístico do município, para discussão de assuntos relacionados ao turismo de Piracicaba, e assim gerar projetos que, como conseqüência, vão aumentar o fluxo de turistas. É o poder público quem deve coordenar esta ação e, assim, aqueles (setor privado) que estiverem interessados em participar realizam as parcerias. Há a falta de um agente agregador que una as forças econômicas e políticas entre os setores, e que atue firmemente com o intuito de direcionar as ações da cidade para o desenvolvimento da estrutura de turismo e, principalmente, da estrutura de divulgação das potencialidades turísticas da cidade. Outra falha do setor público, segundo as empresas, é a falta de informações sobre o que está acontecendo na cidade, não somente em relação ao turismo, mas também sobre ações, empreendimentos que vão ou deixaram de ser feitos no município, para que as ações do trade turístico saibam que direção seguir.

Outro motivo, além do setor público, que dificulta a união dos setores é a falta de visão de alguns empresários locais em relação às vantagens que as parcerias podem trazer a esta área. Muitos desses segmentos seguem sozinhos, cada um por si, não crescendo, às vezes, o quanto poderiam, se estivessem unidos. É necessário que um ajude o outro, trocando informações, pois o turismo é uma área que depende muito de parcerias, funcionando, essencialmente, através destas.

Outro motivo que pode existir é a falta de profissionais experientes nesta área, ou seja, ambos os setores carecem de pessoas com vivência, para que possam ser atingidos os objetivos de que a cidade necessita.

O turismo de Piracicaba tem se desenvolvido apenas por meio de eventos e festas regionais, sem muita divulgação fora da região e sem existência de parcerias entre os agentes envolvidos para uma divulgação mais maciça e mais densa desses eventos.

Portanto, uma forma de parceria que já deveria ter sido realizada, segundo uma empresa, é a ação conjunta através do calendário de eventos da cidade, de modo que, depois de preparado, houvesse uma procura, por parte da SETUR, aos estabelecimentos para conversar e ver maneiras de se poder unir ambos os setores, buscando fomentar o maior número de turistas para a cidade em função desses eventos, mas isso deve acontecer com muita antecedência e com planejamento adequado.

\section{Exemplo de parceria}

Um exemplo de projeto participativo é o modelo desenvolvido no município de Santa Maria Madalena, no Estado do Rio de Janeiro.

O Município, com características predominantemente agropastoris, nos últimos anos teve sua economia fortemente impactada pela queda no valor dos produtos que sustentavam sua arrecadação (leite e outros). A situação econômica crítica levou as lideranças locais ao questionamento do modelo de desenvolvimento desejado para o Município, a médio e longo prazo. Para essa discussão, as lideranças buscavam o apoio de organizações não-governamentais e de universidades e, desde 1996, passaram a trabalhar como a perspectiva de construção de uma estratégia de turismo sustentável, com base nas potencialidades rurais da região e na existência do Parque Estadual do Desengano, uma das principais áreas remanescentes de Mata Atlântica do Estado. É interessante observar que essa unidade de conservação, anteriormente entendida como obstáculo ao desenvolvimento, passou a ser reconhecida como patrimônio regional fundamental para as estratégias futuras em caráter regional.

No caso de Madalena, o projeto não dispôs de recursos internacionais, e a área em foco não tem sido prioridade governamental. No entanto, as iniciativas realizadas em parceria têm permitido um amadurecimento gradativo da comunidade em seu próprio tempo e também sua capacitação para a elaboração de projetos para captação de recursos financeiros. Dessa maneira, as 
lideranças locais passaram a incorporar a perspectiva de integração regional com os demais Municípios de entorno do parque, numa visão estratégica de desenvolvimento. (Irving \& Azevedo, 2002).

\section{Considerações finais}

A partir das comparações entre as entrevistas realizadas com pessoas de ambos os setores, percebe-se que, na cidade de Piracicaba, há uma deficiência visível neste setor, pois, com a falta de parcerias entre os mesmos, Piracicaba deixa a desejar em realizações de pequenos projetos que poderiam estar melhorando e muito a demanda turística da cidade e a vida de todos os envolvidos com o turismo (comunidade, empresas e poder público), pois atualmente se restringe somente ao turismo de negócios.

Piracicaba, com todo o potencial turístico que possui, com suas belezas naturais e culturais, tem o poder de transformar seu turismo de apenas negócios em turismo de lazer, fazendo com que os visitantes venham, e aqueles que já estão fiquem nos fins de semana para passear, conhecendo os atrativos.

Mas, para que isso aconteça, deve haver principalmente o interesse do setor público para incentivar e apoiar a iniciativa privada na união entre os dois setores, de modo que haja realizações de pequenos projetos de melhoria turística na cidade. A existência de parcerias é extremamente importante no desenvolvimento turístico de qualquer que seja a localidade, pois é com a união de forças e interesses que se torna viável a realização de atividades e projetos.

De acordo com Pereira (1999), a variedade de segmentos, atividades e interesses envolvidos no turismo e seu vínculo cada vez mais estreito com os recursos naturais, econômicos, culturais e históricos evidenciam que é fundamental haver maior interação entre as atividades dos diversos grupos e setores da sociedade atuantes na área. Portanto, quanto maior a interação dos setores, maior será sua força e seu poder de realização.

O poder público sozinho não possui condições de realizar projetos pela escassez de verba existente neste setor. Devido a isso, há a necessidade de união deste poder com o setor privado do município, para que se consiga dessa forma realizar melhorias no turismo de Piracicaba, focando no aumento da demanda dos fins de semana, pois, como afirma Beni (1999), "nenhuma instituição pública de Turismo no País poderá prescindir, na atual conjuntura socioeconômica nacional e mundial, da cooperação direta e eficaz da iniciativa privada".

Conforme visto durante todo o trabalho, o poder público deve tomar a iniciativa, o primeiro passo para a realização de parcerias; é dele a responsabilidade de reunir e mostrar ao setor privado sua importância. Todavia, como se pode perceber pelos resultados, não é isso o que acontece na cidade de Piracicaba, pois o Secretário vê a parceria de forma diferente de todos os outros, deixando toda a responsabilidade de sua criação com o setor privado, dando apenas uma ajuda quando necessário em alguma atividade.

De acordo com as empresas privadas, há uma grande falta por parte do setor público, da Secretaria de Turismo, em procurá-las para um parecer sobre o turismo no município e uma oportunidade de união com os diversos setores, pois, para elas, há o interesse e a necessidade dessa união. Portanto, a SETUR deve mostrar mais interesse sobre essa questão, talvez por parte do Secretário, pois, como foi observado por intermédio dos informantes, alguns dos funcionários demonstram certa preocupação em relação ao problema, conhecendo sua verdadeira importância para a cidade.

Nota-se também que, de certa forma, essa preocupação já foi percebida por ambos os setores, e já se pretende colocar em prática a realização de parcerias através da formação do Convention \& Visitor Bureaus de Piracicaba, que deve ter a força e o apoio do setor público e da Secretaria de Turismo.

Sendo assim, uma forma de criar parcerias é pelo CVB e pela união do setor público (SETUR) com este, ajudando e incentivando para que haja melhor divulgação e realizações de projetos em favor do melhoramento turístico do município.

Portanto, o setor público deve aproveitar tal interesse e tornar-se parceiro desta união ( $\mathrm{CVB}$ ), realizando palestras que mostrem como pode ser efetivada essa parceria, os papéis de cada setor e, principalmente, a importância desta para o município. Depois, deve haver também palestras com a comunidade para a conscientização quanto ao turismo e sua importância para o local e, por fim, é necessário fazer com que essas parcerias se tornem realidade, dando ao município a oportunidade de crescimento econômico e, conseqüentemente, de melhorias para a população, em especial para aqueles que vivem do turismo.

\section{Agradecimentos}

Agradeço, primeiramente, a todos os entrevistados, que tornaram meu trabalho viável, respondendo sem hesitação às minhas questões e recebendo-me com muita gentileza em suas empresas.

Com grande carinho, agradeço às amigas e aos familiares que me ajudaram, fornecendo alguns materiais importantes para esta pesquisa. Obrigada também a todos os que, de forma direta ou indireta, me ajudaram na construção deste trabalho. 
Finalizando, agradeço ao professor Henry Lesjak Martos, pela ajuda e disposição em orientar-me com a pesquisa.

\section{Referências bibliográficas}

ALEXANDRE, L. M. M. 2003. Política de turismo e desenvolvimento local: um binômio necessário. In: BEZERRA, D. M. F. (Org). Planejamento e gestão em turismo. São Paulo: Roca. p. 3-13. BARRETTO, M., BURGOS, R. \& FRENKEl, David. 2003. Turismo, políticas públicas e relações internacionais. Campinas: Papirus.

BENI, M. C. 1991. Análise do desempenho do sistema nacional de turismo instituído em administração pública. Tese (Livre-docência) - Escola de Comunicações e da Artes Universidade de São Paulo.

.1999. Política e estratégia do desenvolvimento regional: roteiro metodológico com base na instrumentação e operacionalização do SISTUR - Sistema de Turismo Aplicado ao Projeto da Costa Oeste - Estudo de Caso. Revista Turismo Visão e Ação, Santa Catarina: univalı, ano 2 , n. 3, p. 51-70. abr/set.

CAVALCANTE, K. B. \& HORA, A. S. S. 2002. Política de turismo no Brasil. Revista Turismo em Análise, São Paulo: ECA-USP, v. 13, n. 2, p. 54-73. nov.

COOPER, Chris et al. 2001. Turismo: princípios e práticas. Porto Alegre: Bookman.

CRUZ, A. 2000. Políticas nacionais de turismo e outras políticas setoriais: uma abordagem centrada no território. In: Politica de turismo e território. São Paulo: Contexto.

DENCKER, A. M. F. 1998. Métodos e técnicas de pesquisa em turismo. São Paulo: Futura.

FERREIRA, A. B. H. 1986. Novo dicionário Aurélio da lingua portuguesa. Rio de Janeiro: Nova Fronteira.

GOELDNER, C. R., RITCHIE, J. R. B. \& MCINTOCH, R. W. 2003. Políticas de turismo: estrutura, conteúdo e processo. In: Turismo: princípios, práticas e filosofia. Porto Alegre: Bookman.

IGNARRA, L. R. 2003. Fundamentos do turismo. São Paulo: Pioneira Thompson Learning. IRVING, M. \& AZEVEDO, J. 2002. Turismo, o desafio da sustentabilidade. São Paulo: Futura.

MIGLIANO, F., SCATENA, G. \& CUNHA; T. 2003. Oportunidades de desenvolvimento socioeconômico em localidades rurais com participação da comunidade. In: BEZERRA, D. M. F. (Org). Planejamento e gestão em turismo. São Paulo: Roca. p. 45-52.

MINISTÉRIO DO TURISMO. Plano Nacional do Turismo: diretrizes, metas e programas 2003-2007.

MOURÃO, J. O. F. 2001. Piracicaba 2010 - Realizando o futuro. Piracicaba, sp: Piracicaba 2010. NOGUEIRA, M. F. G. 1987. O papel do turismo no desenvolvimento econômico e social do Brasil. Revista de Administração Pública. Rio de Janeiro: Fundação Getúlio Vargas, v. 21, n. 2, p. 37-54, abr/jun.
- 1983. Políticas públicas: o processo decisório na cúpula do setor de turismo no Brasil. Revista de Administração Pública, Rio de Janeiro: Fundação Getúlio Vargas, v. 17, n. 4 p. 167-182. out/dez.

OMT. 2003. Guia de desenvolvimento do turismo sustentável. Porto Alegre: Bookman.

PEREIRA, C. A. S. 1999. Políticas públicas no setor de turismo. Revista Turismo em Análise. São Paulo: ECA-USP, v. 10, n. 2, p. 7-21. nov.

1999b. Procedimentos para avaliação de políticas públicas pelo Poder Legislativo Estudo de caso da política de turismo de Minas Gerais. Revista do Legislativo, Belo Horizonte $\mathrm{n}^{\mathrm{o}} 25$, jan-mar. (Encarte).

PREFEITURA MUNICIPAL DE PIRACICABA. Secretaria de Turismo. Disponível em: $<$ http:// www.piracicaba2.imagenet.com.br/ccs/>. Acessado em: 8 mar. 2004

ROMERO, S. H. M. 2003. Aproveitamento de oportunidades através da gestão participativa em Icapuí. In: BEZERRA, D. M. F. (Org). Planejamento e gestão em turismo. São Paulo: Roca. p. 54-64.

VERNAGLIA, R. \& GOULART, T. C. 2003. A importância da participação da comunidade local no planejamento e gestão turística de Itanhandú. In: BEZERRA, D. M. F. (Org). Planejamento e gestão em turismo. São Paulo: Roca. p. 116-123.

Recebido em: $16 / 10 / 2004$

Aprovado em: 03/02/2005 